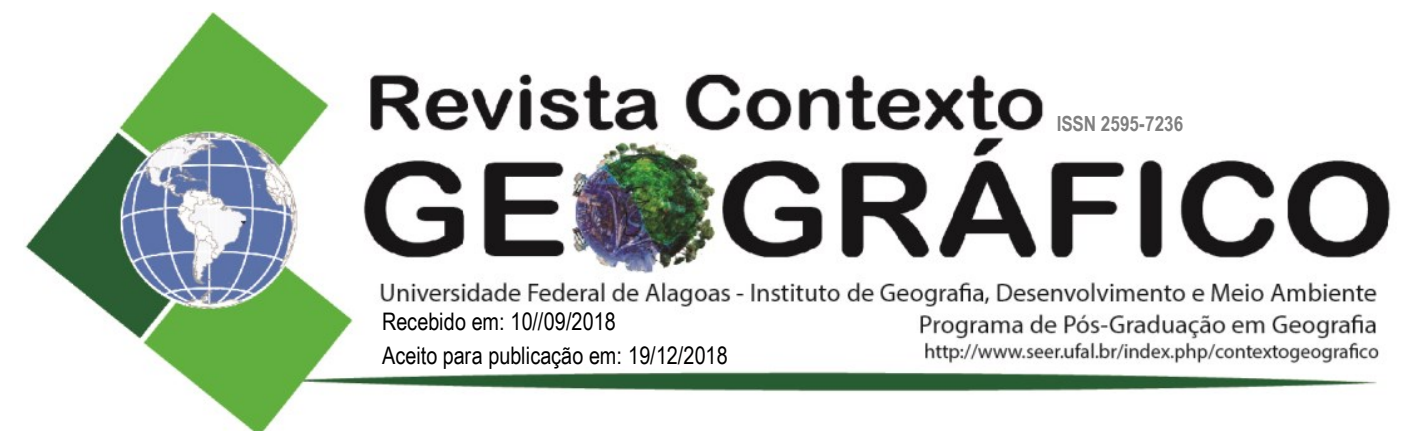

\title{
CLASSIFICAÇÃO DE UNIDADES DE PAISAGEM EM BACIA HIDROGRÁFICA SEMIÁRIDA - UMA ABORDAGEM DO ÍNDICE TOPOGRÁFICA DE UMIDADE
}

\author{
Jônatas Oliveira Vasconcelos \\ Universidade Federal da Paraíba, Departamento de Geociências, João Pessoa, PB, Brasil \\ jonatas.oliveira.vasconcelos@gmail.com \\ Jonas Otaviano Praça de Souza \\ Universidade Federal da Paraíba, Departamento de Geociências, João Pessoa, PB, Brasil \\ jonasgeoufpe@yahoo.com.br
}

\begin{abstract}
RESUMO - O presente trabalho consiste em classificar e caracterizar as Unidades de Paisagens (UP) da bacia hidrográfica do riacho do Tigre, semiárido paraibano. Levando em consideração a influência da distribuição topográfica de umidade sobre os demais elementos e características presentes. A fim de que se cumprisse tal objetivo, utilizou-se dados secundários provenientes de imagens de satélites retiradas da United States Geological Survey, cartografia temática e principalmente trabalhos de campos juntamente com a metodologia do TWI. Tal pesquisa pode ser considerado uma ferramenta chave para um bom planejamento ambiental, tendo em vista demonstrar as características gerais e específicas da área de estudo. Como resultado, o estudo trouxe singularidades de cada uma das cinco UPs encontradas: Pedimentos, Pés de Serras, Encostas Íngremes, Serras e Topo Plano. Esta última apresenta especificidades relevantes para a população e também para a comunidade científica, a grande probabilidade de acumulo d'água, auxiliada pela baixa declividade propiciou a estes ambientes, lugares hábeis para uma utilização com melhores condições de uso e de acesso para a população local. Assim como nessa, buscou-se mostrar as características, pontos positivos e negativos de cada uma delas bem como suas bases de funcionamento.
\end{abstract}

Palavras-chave: TWI, planejamento ambiental, semiárido, Riacho do Tigre.

\section{LANDSCAPE UNIT CLASSIFICATION IN A SEMIARID WATERSHED - NA APPROACH OF TOPOGRAPHIC WETNESS INDEX}

\begin{abstract}
The work is due to classify and characterise as Units of Landscapes (UP) of the catchment area of the Tigre stream, semiarid region of Paraíba. They are taking into account the influence of the topographic distribution of humidity on the other elements and characteristics present. To fulfil this objective the data it was used data from satellite images taken from the United States Geological Survey, thematic cartography and field properties with the TWI methodology were used. Such research can be considered an essential machine for proper environmental planning, to demonstrate the general and specific characteristics of the study area. As a result, the study brought about singularities of each of the UPs: Pedimentos, Saw Feet, Steep Slopes, Saws and Topo Plano. The latter has specificities relevant to a population and also to the scientific community, a high probability of accumulation of water, the help of low declivity provided these environments, is a place for use with good conditions of use and access for the local population. As in this case, we seek to show as characteristics, positives and negatives of each of its bases of functioning.
\end{abstract}

Keywords: TWI, environmental management, semiarid, Tiger watershed. 


\section{INTRODUÇÃO}

Ao passar da história humana, sempre houve à necessidade de buscar formas de se adequar ao lugar e aos métodos que cada época exige. Para isto, formas e métodos científicos foram elaborados de diversas maneiras em diferentes épocas.

Na geografia um dos marcos que revolucionou a forma do pensamento geográfico foi a "Teoria geral dos Sistemas" (TGS), a princípio, tratada por Bertallanffy com sua primeira tentativa de expor uma visão sistêmica em um seminário de filosofia em Chicago. Posteriormente, a TGS foi inserida na corrente geográfica por volta da década de 1950 1960 com Chorley e Sotchava (VICENTE e PEREZ FILHO, 2003).

De acordo com Bertalanffy (1973, p.84), o sistema é um complexo de elementos em interação. Christofoletti, outro estudioso, define este, como um conjunto dos elementos e os vínculos entre eles e suas singularidades (VICENTE; PEREZ FILHO, 2003). Desta forma, a interação entre os diversos elementos se faz necessária para que haja a compreensão de um sistema. Segundo os autores supracitados no parágrafo, o sistema pode ser caracterizado e separado por escalas, sendo essas geográficas, cartográficas ou temporal.

Para este trabalho o sistema escolhido foi o de Paisagens, o qual pode ser subdividido em Unidades para uma melhor compreensão do sistema como um todo. Levando em consideração que não necessariamente o sistema a ser dividido está sendo estudado como complexos separados, isso apenas nos permite ter uma simbolização e uma ampliação dos elementos abarcando-os com maiores detalhes.

Segundo Vitte (2007) a paisagem pode ser observada sobre diversas perspectivas, seja estéticafenomenológica, geopolítica, por sua origem mitológica dentre outras. Para à geografia física a paisagem é a compreensão do processo genético e estruturador das paisagens naturais com auxílio de um instrumental cartógrafo permitindo assim, hierarquizar as paisagens, tratada a princípio por Parssage (VITTE, 2007). Este último ainda afirma que a paisagem é composta pela geologia, relevo, solos e outros elementos que se relacionam no tempo e no espaço, fazendo com que a paisagem se identifique também como um sistema.

Assim, a paisagem se faz presente em praticamente todo lugar, contudo tendo especificidades em lugares diferentes, ou seja, ao mudar de local a paisagem também muda e isto é, principalmente, devido à presença das diversidades dos elementos que compõe um determinado ambiente.

Desse modo, a paisagem se torna um campo de estudo no qual é possível verificar seu tempo e quais os efeitos são ocasionados pelos elementos presentes em uma região. Para tal, a compreensão da paisagem implica conhecimento sobre os estudos da hidrografia, clima, solos, fauna e flora, estrutura ecológica, o uso do solo e todas as outras expressões da atividade humana ao longo do tempo (PINTOCORREIA et al., 2001).

Vista a partir de uma forma sistêmica, a paisagem considera os elementos ambientais e a inter-relação entre eles, dando forma as diversas variações de paisagens (VICENTE e PEREZ FILHO, 2003).A exemplo disto está a interação da geologia com o clima, de modo que esta controla os processos intempéricos, influenciando a formação de solos, estrutura e morfologia superficial do relevo.

Com isso, o presente estudo adentra na perspectiva geossistêmica, fundamentada sobre a TGS, contudo com as considerações e relevâncias geográficas para um estudo. Bertrand (2004) afirma que o geossitema é uma forma concreta do espaço, resultado da interação do potencial antrópico, potencial ecológico e o potencial biológico e sua exploração. Sotchava (1977) também discute o conceito de geossistema e afirma que seria um sistema territorial em natura que é elaborado por elementos naturais e suas interrelações no decorrer do tempo.

Desta forma, seguindo o pensamento geossitêmico e também a lógica do estudo por unidades é que surge a importância e a caracterização do estudo por Unidades de Paisagens (UP). Para Bertrand (2004) a UP é uma categorização homogenia de uma região. Assim, a categorização da UP se torna 
um campo de trabalho para os estudos geossistemicos da paisagem (CHRISTOFOLETTI, 1999). Desta forma, a associação dos elementos que compõe e interagem no geossistema solidifica a relação entre os potenciais ecológicos, as explorações biológicas e a maneira como esses variam no espaço de acordo com o tempo, tecendo uma dinâmica ao Sistema Ambiental Físico que para Christofoletti (1999) é o mesmo que geossistema (CHRISTOFOLETTI, 1999).

Bertrand (2004) aprofundando tal conhecimento sobre a Unidade de Paisagem, estabelece que esta é uma porção espaço-temporal bem definida e que têm variáveis e interações ambientais especificas diferenciando-se das demais áreas, mostrando a partir dessas diferenças, o porquê dos efeitos e causas das áreas próximas.

Dentre muitos outros elementos existentes na bacia hidrográfica em questão, um fator muito significativo na caracterização das UPs de São João do Tigre (figura 1), é a hidrologia. Sua importância se dá, principalmente, pelo controle da quantidade de formação de sedimentos, assim como no auxílio da proliferação da cobertura vegetal, como também o reabastecimento dos aquíferos, poços e açudes locais e regionais. Desta forma, a hidrologia aqui, é muito importante e um elemento chave na caracterização das Unidades de Paisagens.

A hidrologia segue um padrão, sendo necessário antes de sua utilização, um arcabouço teórico para definir e auxiliar a hidrologia local, desta maneira, o modelo hidrológico, para fins científico, se encaixa no perfil e na caracterização da presente área de estudo.

Segundo Santos (2009) o modelo hidrológico serve como uma ferramenta e afirma que a modelagem hidrológica propicia apurar a consistência dos informes acessíveis (os dados observados no estudo), que são geralmente curtos, conseguidas a partir de observações hidrológicas nas áreas de captação de água. Com alicerce nesses dados, os modelados hidrológicos podem ser regulados e um exemplo dessa calibração seria lograr dados em bacias não monitoradas (SANTOS, 2009).

Nos modelados hidrológicos existem dois tipos básicos de difusão da água. O escoamento superficial que controlará a distribuição da água na paisagem. E o escoamento subsuperficial, gerado após o processo de infiltração, em que este se caracteriza por distribuição e deslocamento mais lento da água.

A infiltração faz parte vultosa do ciclo hidrológico e é mais que uma entrada de água no solo, a mesma faz a repartição da água fornecida à bacia hidrográfica, através das precipitações, em duas partes distintas, porém que se complementam. A primeira delas adentra na superfície do solo recarregando a umidade das camadas superiores e inferiores do solo. A segunda delas infiltra para os locais mais profundos reabastecendo os aquíferos ou indo para lugares mais profundos devido a fendas ou outros fatores (SOUSA, 2009). A infiltração é importante não só para área em questão, mas para diversas áreas no mundo, vale salientar que há ainda quatro processos principais que interferem na infiltração, são eles; os tipos de solos, o grau de umidade, os efeitos da precipitação e a cobertura vegetal (SOUSA, 2009)

Segundo Lucena et al. (2012) a hidrologia é um fator importante na formação do solo e no desenvolvimento da vegetação, de modo, que a água junto com os sedimentos e suas interações químicas-físicas produz a formação dos solos, assim como a água com os poros e partículas d'águas existentes nos solos juntamente com as águas provenientes das precipitações, modificam e definem $o$ tipo de vegetação.

A partir disso o entendimento da distribuição da água em superfície e subsuperfície rasa (saturação de água no solo) é de vital importância, especialmente para a área analisada nesse estudo, localizada no semiárido brasileiro, possibilitando uma melhor gestão territorial; tendo em vista as condições climáticas caracterizadas pelo déficit hídrico (ARAUJO e SOUSA, 2013).

O semiárido do nordeste brasileiro embora apresente déficit hídrico é extremamente diverso em muitos aspectos, apresentando variados elementos que podem interferir na distribuição da umidade superficial e subsuperficial (CONTI, 2005). A exemplo disso é a variação do volume de precipitações que variam de 300 a $800 \mathrm{~mm}$ anuais em média (CONTI, 2005), ou a variação de altitude que 
proporciona um aumento dos níveis de precipitação e umidade, podendo inclusive definir enclaves subsumidos (SOUZA e OLIVEIRA, 2006).

Assim como a hidrologia e o clima, o relevo afeta diretamente na distribuição da hídrica (umidade) em nível local, influenciando, entre outros fatos, o tempo de estadia da água na Paisagem de São João do Tigre. Além disso, este, funciona como controlador da declividade, assim, regulando a velocidade do escoamento e a dispersão da água que são provenientes das precipitações. A velocidade do escoamento aumenta proporcionalmente a declividade, tanto o superficial como o escoamento subsuperficial, com isso a concentração de água em lugares com a declividade mais acentuada é menor. Se o relevo tem menos declividade, a velocidade de escoamento tende a ser menor. Assim, o solo neste determinado relevo passa a ter uma competência de infiltração maior, e o tempo de estadia (concentração) da água também (CORREA, SILVA e MELO, 2008).

O tempo de estadia da água assim como a probabilidade de acúmulo d'água e demais assuntos pertinentes a hidrologia é de vital importância para toda a sociedade, tendo em vista que é uma das necessidades básicas para quase tudo na Terra, desta forma estudar este elemento se faz necessário e uma das técnicas para tal é a do TWI (Topographic Wetness Index), técnica que permite através da declividade e do relevo e dos dados do clima, propor áreas com maiores e menores probabilidades de acúmulo d'água tratada por Beven e Kirkby (1979). O TWI então, visa buscar os índices de umidade de uma determinada região, geralmente, com o objetivo de auxiliar um outro estudo ou elemento como por exemplo a vegetação e solos.

O TWI ao captar o índice de umidade potencial, propõe a quantidade de água acumulada favorecendo aos estudos visões mais complexas para entender o porquê determinado elemento se desenvolve daquela forma (JENCSO; MCGLYNN, 2011). Por exemplo: ao calcular uma grande quantidade de água acumulada sabe-se que o solo tem uma alta capacidade de infiltração o que favorece o escoamento dependendo da declividade.

Contudo, o presente estudo visa caracterizar e classificações as Unidades de Paisagens, que tratadas por Rodriguez e Silva (2002), apontam duas possibilidades. A primeira delas - seria à necessidade de diferenciar as paisagens e a outra identificar as diferentes formas de se ocupar um espaço. Então à medida que se obtêm uma classificação até mesmo uma hierarquização da área de estudo, as Unidades de Paisagens passam a ser de vital importância e se tornam subsidio para o planejamento em uma Bacia Hidrográfica, pois é possível trazer à tona mais detalhes do local de estudo.

A partir do exposto, a Bacia Hidrográfica do Riacho do tigre, se encaixa em condições que permitem a análise a ser proposta mediante às bases teóricas já expostas, esta é uma área que necessita de estudos mais aprofundados, devido a existência de uma das maiores áreas de proteção ambiental da Paraíba, a APA das Onças, além da carência de estudos em áreas semiáridas, e principalmente na região a qual se encontra esta área de captação.

Desse modo, o presente estudo visa realizar a classificação das UPs da bacia do Riacho do Tigre, semiárido paraibano, baseado nas informações ambientais básicas (geologia, elevação, declividade, clima, solos e uso e cobertura da terra), além de informação sobre a distribuição de umidade na paisagem (TWI). Posteriormente, caracterizando e mapeando tais Unidades de Paisagens.

\section{METODOLOGIA}

O município de São João do Tigre tem sua área equivalente a $816 \mathrm{~km}^{2}$ e população total de 4.396 habitantes (IBGE, 2010) e faz divisa com Pernambuco. A área da Bacia Hidrográfica propriamente dita tem cerca de $569.4 \mathrm{~km}^{2}$ e se encontra em uma microrregião do cariri ocidental da Paraíba, na mesorregião da Borborema, mais precisamente, nas proximidades do lineamento ParaíbaPernambuco, e possui clima típico dessas regiões, semiárido tropical (BRASIL, 2005). A grande variação de altitude desta área tem influência direta nos processos que ocorre nesta mesma área de captação. Esta variação de altitude se dá principalmente pela presença de unidades geomorfológicas distintas dentro do Planalto da Borborema, que na área divide-se em duas subunidades a Depressão 
Intraplanaltica Paraibana e os Maciços Remobilizados do Domínio da Zona Transversal (CORRÊA et al, 2010).

Segundo os autores Corrêa et al. (2010) a Depressão Intraplanaltica da Paraíba encontra-se na porção central da Borborema paraibana, em que os seus limites se dão a leste e oeste pelos compartimentos de encostas. Os mesmos, falam sobre a Depressão Intraplanaltica da Paraíba que: a ausência de um distúrbio tectônico com mais intensidade propiciou o desenvolvimento de feições planas, em que se limitam no Sul com os Maciços Remobilizados do Domínio da Zona Transversal, e que o clima predominante, semiárido, não permite o regolito se desenvolver, expondo gnaisses e migmatitos na superfície.

Os Maciços Remobilizados do Domínio da Zona Transversal que são limitantes do desenvolvimento de feições planas e que é fator vital no controle e variação da altitude nesta área, é caracterizado como a área morfologicamente mais atingida pelos arqueamentos os quais tiveram atuação sobre o planalto, expondo assim as cimeiras mais elevadas e os relevos mais tenros. Expondo assim que há uma sucessão nestes relevos de maciços isolados, cristas e depressões intraplanálticas estreitas. Onde, esta zona é vigorosamente conservada pela presença de intrusões brasilianas (CORRÊA et al, 2010)

O reflexo dos processos provenientes da altitude local está presente nas Unidades de Paisagens, produzindo zonas de produção de sedimentos com mais precipitações nas áreas mais altas e zonas de deposição de sedimentos com mais intensidades de escoamentos nas partes mais baixas.

Deste modo, a Bacia hidrográfica do Riacho do Tigre, foi definida a partir dos parâmetros de altitude, umidade, e da própria extensão das redes de drenagem locais, sendo primeiramente definida em mapa real, depois ratificado na modelagem hidrológica do software ArcGisTM 10.2.

Para as classificações das Unidades de Paisagem da bacia hidrográfica do Riacho do Tigre, foi utilizado a forma ou tipologia, e a regionalização. A primeira sendo uma diferenciação nas suas semelhanças e repetições, tendo dependência de parâmetros de homogeneidade e a segunda à determinação das paisagens conforme sua individualidade e sua personalidade (CAVALCANTI, 2014).

Em auxílio aos métodos escolhidos foram agrupados dados temáticos secundários provenientes do Zoneamento Agroecológico de Pernambuco de escala de 1:100.000 com exceção do Modelo Digital de Elevação (MDE) obtidos por meio de imagens do satélite SENTINEL 2B com resolução de 30 metros disponibilizado pela USGS (United States Geological Survey), afim de que juntamente com os trabalhos de campos fosse possível demarcar as Unidades de Paisagens com melhores detalhes.

Tendo em vista que a hidrologia é um fator muito importante na área de estudo, foi tomado um padrão específico, dando mais ênfase a esta variável por sua importância. Assim, no tocante a distribuição da água superficial utilizou-se a técnica do TWI (Topographic Wetness Index). Sendo também utilizado como uma informação auxiliar para caracterização e classificação das Unidades de Paisagem. $O$ uso desta técnica foi da mesma maneira realizado no software ArcGisTM 10.2, a partir do método tratado por José e Ulrich (2012) com a fórmula utilizada pelos mesmos:

$$
\ln \left(\frac{\text { fluxo acumulado }}{\text { tangente da declividade }}\right)
$$

Levando em consideração o fluxo acumulado, a direção de fluxo e a declividade do relevo.

Para uma melhor compreensão dos dados obtidos a partir do TWI, os valores foram distribuídos em cinco classes, muito baixo, baixo, mediano, alto e muito alto. Implicando na probabilidade de acumulo de umidade, consequentemente de água em um determinado local. Em que, teoricamente, se a probabilidade de umidade aumenta, a quantidade de água também, e se menor a probabilidade tende a ter uma menor a quantidade de água.

Assim, com as classificações das paisagens presentes e a delimitação da Bacia Hidrográfica foi produzido a carta temática de Unidades de paisagens. Esta contém à compilação de todos as cartas 
temáticas, expondo as suas especificidades de acordo com cada elemento presente, gerado através do software ArcGis 10.2 com suas ferramentas.

\section{RESULTADOS E DISCUSSÃO}

O presente estudo buscou expor uma visão mais ampla sobre o local de estudo, integrando tanto seus elementos primários existentes quanto a probabilidade de disponibilidade hídrica assim como a de umidade. Compondo um geossistema trazendo características mais precisas sobre a Bacia Hidrográfica do Riacho do Tigre. Trazendo como resultado tanto dados de características gerais como características mais específicas.

Com a análise a partir dos métodos e matérias utilizados, pode-se então obter uma divisão das Unidades de Paisagens presentes na bacia hidrográfica do Riacho do Tigre norteando os elementos contidos no local assim como o estudo como um todo. Gerando tanto a carta temática geral do TWI como as das UPs que se dividem em cinco unidades, sendo elas; Pedimentos, Pé de Serras, Encostas Íngremes, Serras e Área de topo Plano (Figuras 1 e 2).

A divisão das UPs foi feita a partir das variáveis encontradas no local como já exposto na metodologia, utilizando os solos, relevos, declividade, geologia, uso e cobertura assim como a umidade e a probabilidade de acúmulo d'água, gerando áreas distintas de acordo com suas especificidades.

A primeira UP a ser explanada será a Unidade de Paisagem de Pedimento (UPP, figura 3). Esta, está localizada nas altitudes mais baixas, e em maioria de sua extensão composta por superfícies mais aplainadas. Isto influencia diretamente em toda a dinâmica local.

No tocante ao uso e cobertura, possui ao todo, aproximadamente $313 \mathrm{~km}^{2}$, sendo $170 \mathrm{~km}^{2} \mathrm{de}$ vegetação arbustiva arbórea aberta, $118 \mathrm{~km}^{2}$ de áreas antropizadas e $25 \mathrm{~km}^{2}$ de caatinga arbustiva arbórea fechada. Isto em grande parte, se dá pelo fato de que seu solo é basicamente coberto por Neossolos Litólitos Eutróficos (aproximadamente $243 \mathrm{~km}^{2}$ ).

Este tipo de solo possui a camada " $\mathrm{A}$ " menos espessa e em sua maioria composto por textura mais arenosa, propiciando uma evaporação mais rápida da água. Em solos com essas características, os poros geralmente se encontram mais "soltos" facilitando a entrada dos raios solares, intensificando o efeito da evaporação, evidenciando a probabilidade do acúmulo d'água obtido no TWI.

Figura 1. Mapa de localização e Mapa de Unidades de Paisagens da Bacia Hidrográfica do Riacho
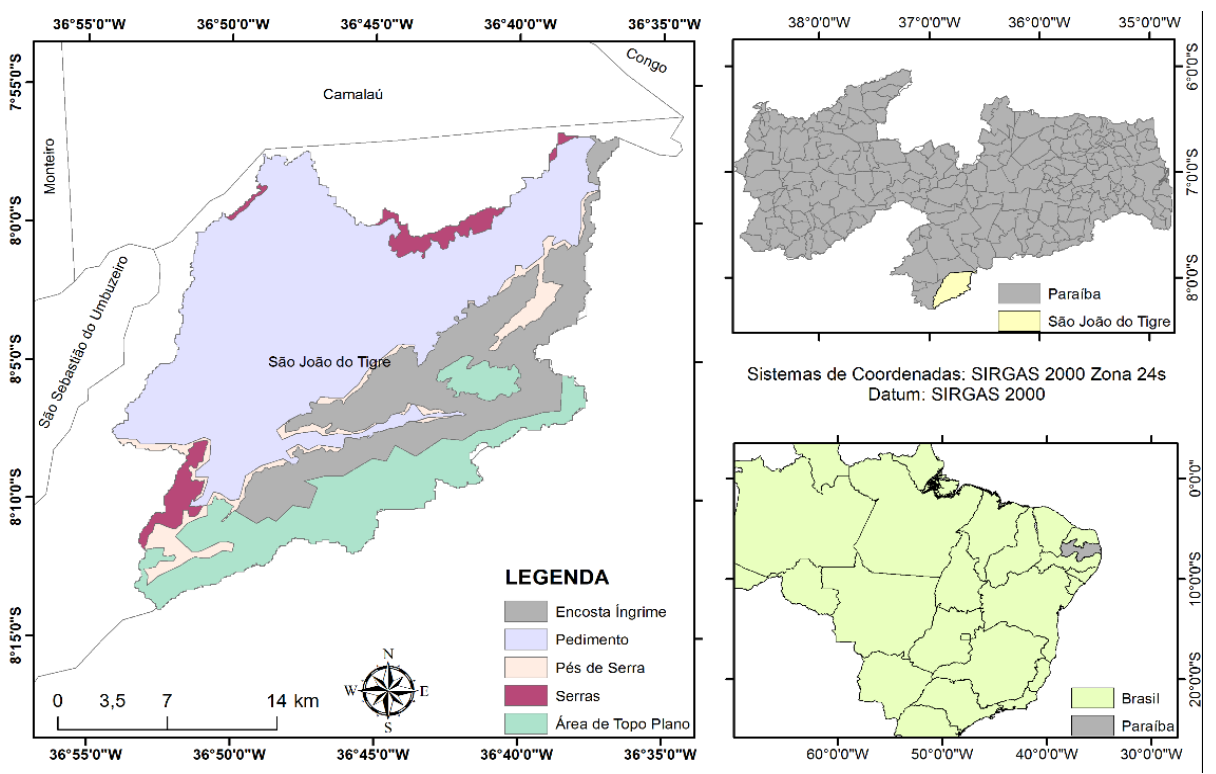

Elaboração: VASCONCELOS e SOUZA (2017) 
Figura 2. Carta temática do TWI da Bacia Hidrográfica do Riacho do Tigre

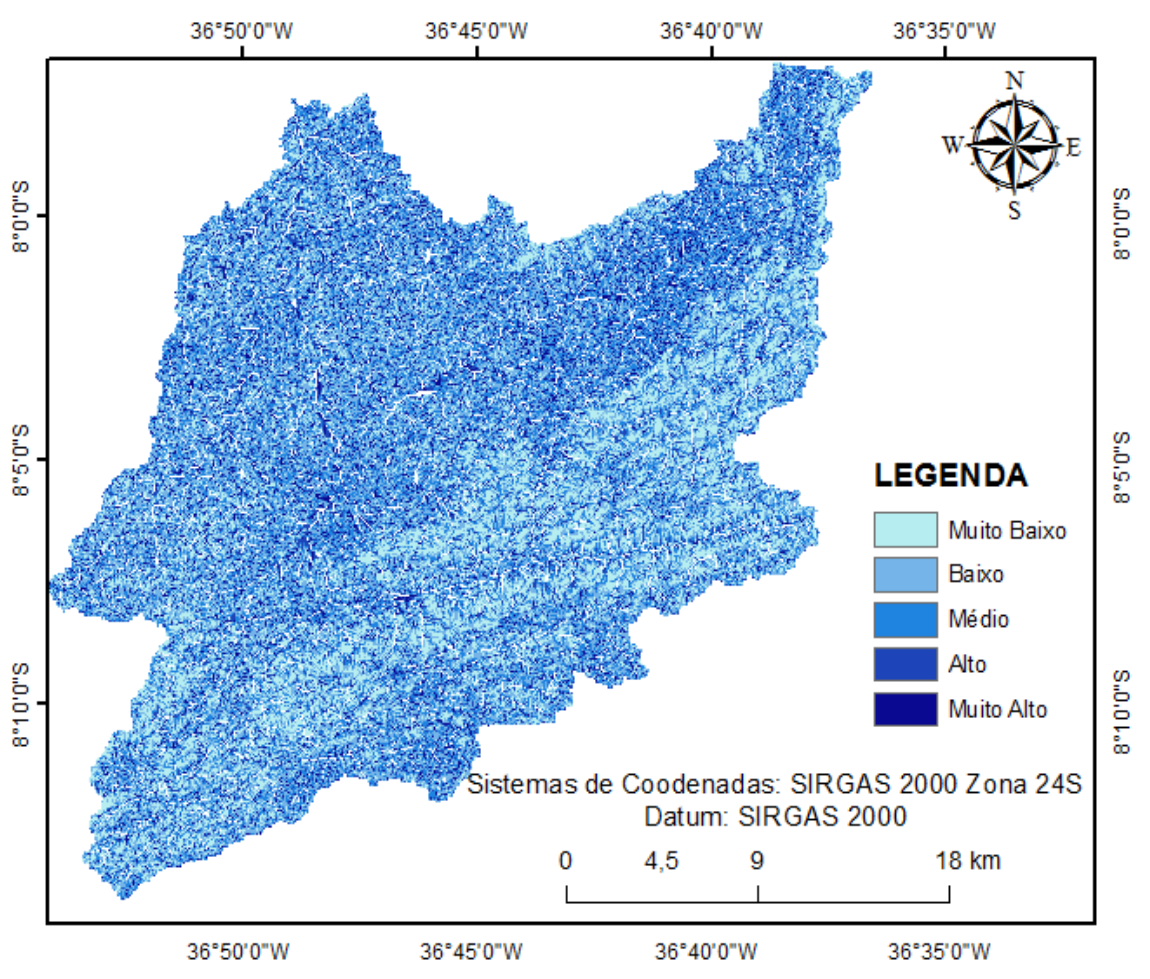

Elaboração: Os Autores

Figura 3. Carta Temática de TWI e declividade da UP de Pedimento
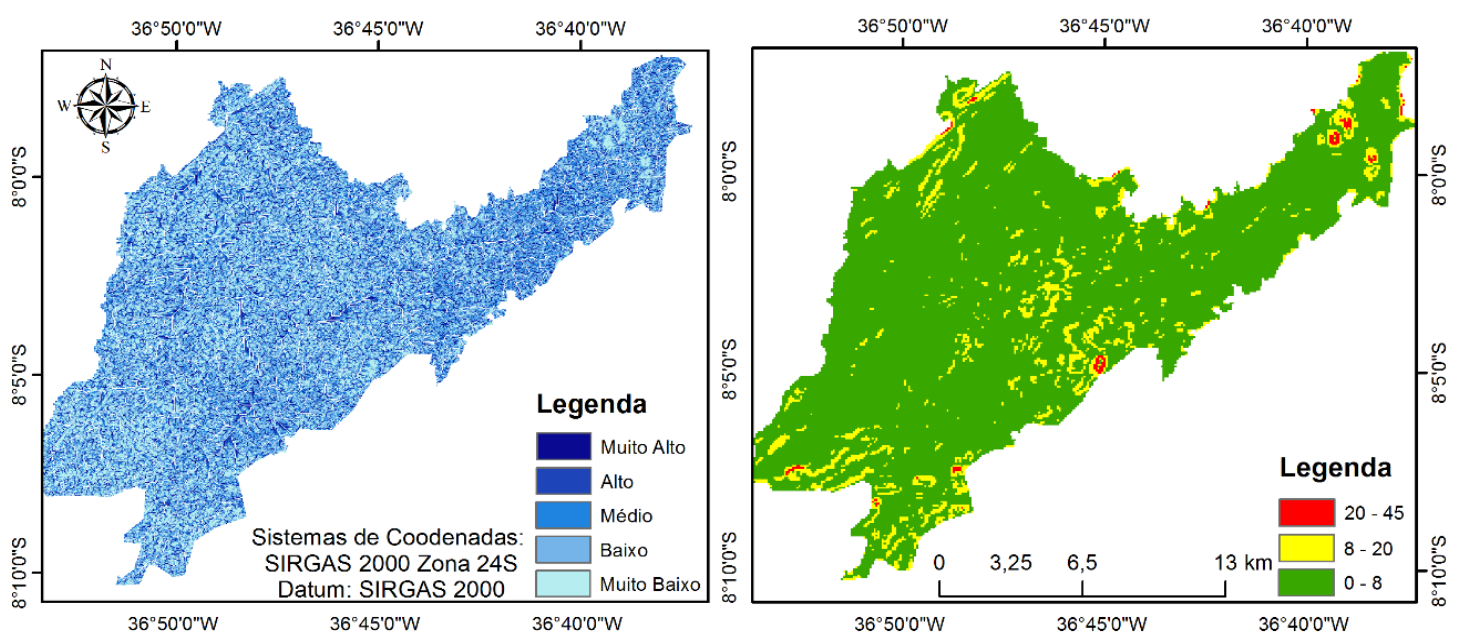

Elaboração: Os Autores

Predominando os índices de TWI de baixo a média probabilidade de água, mais um fator que propicia a característica da vegetação amis aberta nessas áreas, consequentemente expondo o solo cada vez mais aos impulsos inseridos no sistema dessa UP. Mesmo sendo uma área de depósito de pedimentos e tendendo a receber mais desagues dos rios adjacentes, devido ao grande período seco em áreas semiáridas e a peculiaridade já vista acima a disponibilidade de água acaba por ser menor.

A geologia dessa UPP (composta basicamente composta por Granito e granodiorito e Metadacito, Metapelito, Paragnaisse, Quartzo, Rocha Metavulcânica), tende a acrescentar na questão dos 
grandes índices de evaporação. Ao se ter um solo basicamente de camada "A" menos espessa e logo abaixo uma geologia compacta e resistente, a água não penetra ficando a disposição da evaporação, facilitando também a salinização do solo proveniente do soerguimento dos sais e consequentemente com a evaporação da água os sais acabam por se depositar na superfície. Sendo também fator determinante na presença de vegetações mais abertas.

Porém mesmo com os fatos já relatados, é uma área plana e de acesso mais fácil à população, sendo assim uma área de uso constante, podendo se considerar esta UP uma Unidade atípica

Na UP Pé de Serra (UPPS) se localiza entre as Unidades de Pedimentos e Encostas ìmgremes. Nestas há também uma predominância do solo Neossolo Litólito Eutrófico (apriximadamente 35 $\mathrm{km}^{2}$ ). Por estarem localizadas próximas as Encostas Íngremes, esta UP é afetada pela umidade proveniente das Encostas, caracterizando eventuais chuvas orográficas (chuvas provocadas por uma barreira, neste caso as encostas), sendo evidenciado e caracterizado pelo TWI com certa precisão, encontrando índices de média a alta probabilidade de acúmulo d'água.

Outro fator presente é a declividade que agora já possui valores de $8 \%$ a $20 \%$, sendo mais íngreme que a UP anterior, auxiliando o escoamento da água para as proximidades inferiores, propiciando predominância de vegetações de caatinga arbustiva arbórea fechada $\left(19 \mathrm{~km}^{2}\right)$ e caatinga arbórea aberta $\left(24 \mathrm{~km}^{2}\right)$. Contudo, por não ser tão íngreme, ainda se encontra antropismo nessa UP com média aproximada de $10 \mathrm{~km}^{2}$.

No tocante a sua formação geológica, é possível observer uma equivalência entre Metagranito, Metagranodiorito e Granito e Granodiorito (AESA, 2017). Esta área possui apriximadamente $24,5 \%$ de sua área já antropizada, demonstrando que mesmo com dificuldades, as dificuldades fazem com que a população procure nosvos meios para utilizar os recursos disponíveis pela natureza e o recurso hídrico é apenas um exemplo disto.

A UP denominada Encosta Íngreme, possuem as áreas mais preservadas dentre todas as outras, principalmente devido ao sua declividade possuir intervalos altos, que vão de $20,01 \%$ a $114,7 \%$. Embora estas também possuírem em sua maioria o solo Neossolo Litólito eutrófico, a declividade presente, fornece uma quantidade razoável de água, priveniente, principalmente, do escoamento superficial ao longo das encostas, e que por essas áreas possuírem um acesso mais difícil resultam em uma vegetação mais densa e fechada devido a não exploração em massa da mesma. Tendo vegetação basicamente composta por caatinga arbustiva arbórea fechada (aproximadamente $195 \mathrm{~km}^{2}$ ).

Devido a isso, se torna um pouco inviável (ou imprópria) para o uso, pois devido a vegetação mais densa e fechada, possibilita com maior frequência a aparição de felinos de grande porte, sendo não muito interessante criar gado ou outros tipos de animais nas mediações.

No tocante a geologia estas áreas são compostas principalmente por Granito e Granodiorito, porém com outras porções menores de Monzogranito, Metagranito e Metagranodioritos. Mesmo possuindo tal solo e composição geológica e o TWI apresentando valores médios, há um aproveitamento significativo da natureza para sua dinâmica nestas Unidades.

Na UP chamda de "Serras" há uma variação maior de declividade, sendo áreas praticamente inutilizadas pela população local, embora possuam temperaturas mais amenas (BORGES, 2013). $\mathrm{Na}$ área estudada estas Serras se encontram em lugares distintos cartograficamente, e por motivos de praticidade e fácil compreensão serão expressas como as localizadas ao norte e ao sul da bacia.

Em relação às do Norte da bacia, há presença apenas de Neossolos Litólitos Eutróficos e antropismos além de ser completamente composta geologicamente por Granitos e Granodioritos. Já nas encontradas ao sul, além dos Neossoslos Litólitos Eutróficos há presença de Luvissoslos (solos com horizonte B textural e argila de atividade alta), possui vegetação composta por Caatinga Arbustiva Arbórea Fechada e não apresenta indícios de antropismos. No tocante a geologia é composta por Metadacitos, Metapelito, Paragnaisse, Quartzo e rochas Metavulcânicas além de uma pequena porção composta a partir de Granitos e Granodioritos. 
No geral as Serras possuem $13 \mathrm{~km}^{2}$ de Neossolos Litólitos Eutróficos, e apenas $3 \mathrm{~km}^{2}$ de Luvissolos nas Serras ao sul da Bacia. O TWI mais uma vez ratifica a probabilidade de acúmulo d'água nesta UP, no qual a partir do mapa gerado verifica-se muito baixo acúmulo d'água, pois a água que ali é exposta, acaba por escoar, ficando apenas pequenas quantidades que logo são evaporadas devido a ação dos raios solares, que auxiliados pela geologia só há o aceleramento deste processo.

A quinta UP, denominada Topo Plano, é a que mais apresenta diferenças no tocante a diversisdade dos elementos presentes. Por ser uma área mais plana possui declividade bem estável, com seus índices variando de $8,1 \%$ a $20 \%$. No que diz respeito aos solos, estes além dos Neossolos Litólitos Eutróficos, comum em quase toda a área de estudo, também apresenta areas cobertas por Neossolos Regolíticos.

Sua vegetação também se diversifica muito, sendo coberta por caatinga arbustiva arbórea fechada, caatinga arbustiva arbórea aberta mais ao sul e oeste da bacia ainda se encontra área de Caatinga Arbórea Fechada, mais ao sudoeste dessa UP e no centro tem o domínio do Antropismo.

Esta última categora (o antropismo), a cada dia passa a ser mais presente na realidade desta UP, devido a maior probabilidade de acumulo de umidade e água, principalmente, devido à sua altura e a predominância de uma superfície mais plana, fazendo com que as águas remanescentes das chuvas acabem formando áreas alagadas ou áreas com maiores possibilidades de infiltração tanto para camadas mais profundas do solo ou até mesmo para aquíferos, tornando essas áreas bem mais propícias para o uso da população local.

No tocante a geologia tem-se um divisão entre Metagranito, Metagranodiorito, Granito, Granodiorito e Monzogranito. Esta última UP tem especificidades bem acentuadas na Bacia do Riacho do Tigre, diferentemente da Unidade de Pedimento, esta possui acúmulo d'água de médio a muito alto (mesmo o mapa demonstrando muito baixo em alguns locais, isto se deve a área de captação da bacia, modificando assim no software os resultados). Este acúmulo e absorção de água se deve por estar emu ma superfície mais plana e está localizada nas partes mais altas da bacia. Deste modo, a água que ali é exposta acaba que infiltrando e não escoando, fazendo com que tenha uma quantidade maior de água em comparação com as outras Unidades de Paisagens.

Por estas razões supracitadas e pelo fato que esta deve ser uma área a ser enfatizada para o uso de forma correta da terra, a fim de que permita desenvolvimentos mais proveitosos para a sociedade local, que foi apresentada a Figura 4, isolando os principais elementos nesta UP, o TWI e Declividade.

Figura 4. Carta de TWI e declividade da Unidade de Paisagem Topo Plano.
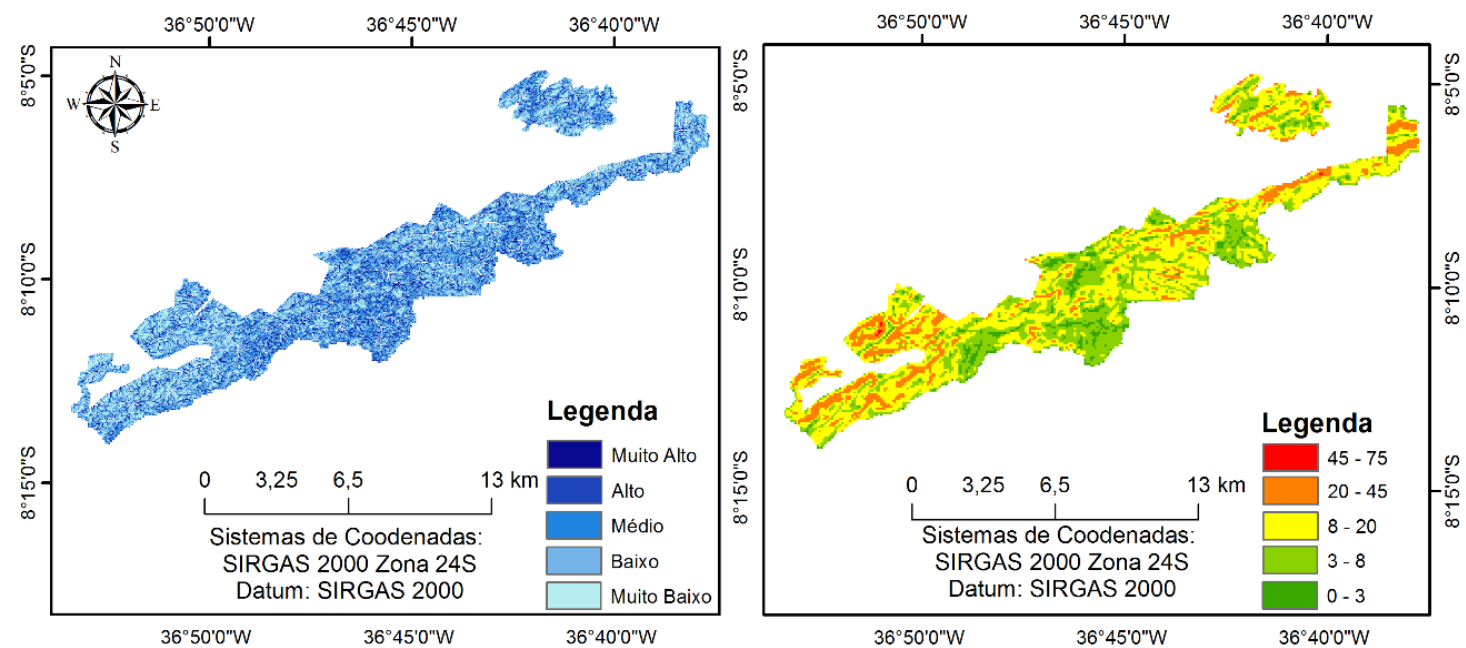

Elaboração: Os Autores 


\section{CONSIDERAÇÕES FINAIS}

$\mathrm{O}$ estudo de Unidades de Paisagens como o que aqui se compreende, revela propriedades e especificidades importantes do determinado local de estudo, possibilitando o auxílio tanto a comunidades científicas como a população em geral. Fazendo com que as áreas que compõem as UPs aqui apresentadas, possuam usos mais adequado, e se avalie áreas mais adequadas ou não para determinados tipos de uso, como plantação, criação de gado, escavação de poços e etc.

Esta importância de estudos com análises hídricas em locais como este é importante, pois muitos dos povoados que moram nas áreas mais distantes dos rios ou até mesmo que moram perto dos canais do rio principal, passam a maior parte do tempo com rios ou drenagens secas. Desta forma, é possível também auxiliar a descoberta de possíveis aquíferos só pelo fato destes conhecimentos nos propiciar mais certeza que determinadas áreas tendem a ser mais úmidas e alagadas que outras. Este exemplo com a água é devido a importância da água no território semiárido, pois na maioria das vezes as populações do semiárido sofre por problemas hídricos.

\section{REFERÊNCIAS}

ARAUJO, W. S.; SOUSA, F. A. S. Identificação de regiões pluviometricamente homogêneas no nordeste do Brasil usando análise multivariada. Curitiba, Revista Brasileira de Climatologia, v. 10, n. 1, p. 136-152, 2013.

BERTRAND, G. Paisagem e geografia física global: Esboço metodológico. Curitiba, RA'E GA - O Espaco Geografico em Analise, v. 8, n. 8, p. 141-152, 2004.

CONTI, J. A Questão Climática Do Nordeste Brasileiro E Os Processos De Desertificaçâo. Aracajú, Revista Brasileira de Climatologia, v. 1, p. 7-14, 2005.

CORRÊA, A. C. B et al. Megageomorfologia e Morfoestrutura Do Planalto Da Borborema. São Paulo, Revista do Instituto Geológico, v. 31, n. 1/2, p. 35-52, 2010.

CORREA, A. C. B.; SILVA, D. G.; MELO, J. S. Utilização Dos Depósitos De Encostas Dos Brejos Pernambucanos Como Marcadores Paleoclimáticos Do Quaternário Tardio No Semi-Árido Nordestino. Fortaleza, Mercator, p. 99-126, 2008.

IBGE. Panorama de São João do Tigre. Disponível em: <https://cidades.ibge.gov.br/brasil/pb/sao-joao-dotigre/panorama>. Acesso em: 15 jan. 2017.

JENCSO, K. G.; MCGLYNN, B. L. Hierarchical controls on runoff generation: Topographically driven hydrologic connectivity, geology, and vegetation. Water Resources Research, v. 47, n. 11, p. 1-16, 2011.

JOSÉ, R. L.; ULRICH, K. Uso Del Indice Topografico De Humedad (Ith) Para El Diagnóstico De La Amenaza Por Desborde Fluvial, En Trujillo - Venezuela. Universidad de los Andes Trujillo, Venezuela, v. 1, n. 1, p. 109-126, 2012.

LUCENA, J. A. et al. Análise Da Variabilidade Da Precipitação Pluviométrica Como Subsídio Para O Planejamento Agrícola Em Caicó/Rn. Revista Brasileira de Meteorologia, v. 10, n. 1980-55, p. 121-135, 2012.

PINTO-CORREIA, T.; C ANCELA D’ABREU, A.; OLIVEIRA, R. IDENTIFICAÇÃO DE UNIDADES DE PAISAGEM: Metodologia aplicada a Portugal Continental. Finisterra, v. 36, n. 72, p. 195-206, 2001.

SANTOS, L. L. DOS. Modelos hidráulicos-hidrológicos: Conceitos e Aplicações. RBGF-Revista Brasileira de Geografia Física Recife-PE, v. 203, n. 3, p. 1-19, 2009.

SOTCHAVA, V. O estudo de geossistemas. Revista Instituto de Geografia da Universidade de São Paulo, 1977.

SOUSA, F. A. S. DE. Estimativa da precipitação excedente em Ipojuca, PE. v. 13, n. 83, p. 716-723, 2009. 
SOUZA, M. J. N.; OLIVEIRA, V. P. V. Os Enclaves Úmidos E Sub-Úmidos Do Semi-Árido Do Nordeste Brasileiro. Mercator, v. 5, n. 9, p. 85-102, 2006.

VICENTE, L. E.; PEREZ FILHO, A. Abordagem sistêmica e geografia. Geografia, v. 28, n. 3, p. 323-344, 2003.

VITTE, A. C. O DESENVOLVIMENTO DO CONCEITO DE PAISAGEM E A SUA INSERÇÃO NA GEOGRAFIA FÍSICA. Revista de geografia da UFC, v. 11, p. 71-78, 2007.p. 